\title{
Review of Immobilization Devices and Motion Management Techniques in Accurate Delivery of 4D-SBRT
}

\section{Pawan Kumar}

Department of Radiation Oncology, Jaypee Hospital, sector-128, Noida, Uttar Pradesh -201304, India

*Corresponding author: Pawan Kumar, Sr. Radiation Therapist, Department of Radiation Oncology, Jaypee Hospital, sector-128, Noida, Uttar Pradesh -201304, India, Tel: 91-9910958971; E-mail: pawankumar183g@gmail.com

Received date: Apr 25, 2015, Accepted date: Aug 21, 2015, Publication date: Aug 24, 2015

Copyright: (C) 2015 Kumar P. This is an open-access article distributed under the terms of the Creative Commons Attribution License; which permits unrestricted use; distribution; and reproduction in any medium; provided the original author and source are credited.

\section{Objective}

To review the accuracy and efficacy of immobilization and motion management techniques for delivering ablative doses to tumors with limited normal tissue toxicity.

\section{Methods and Materials}

10 Patients selected with lung, liver and spine cases.

\section{Immobilization devices for SBRT}

Body fix: Thoracic sheet or pelvis sheet are used over the patients with manifold cushions and vacuum is created between patient and sheet.

Abdominal compression: To minimize respiratory induced tumor mobility for both lung and liver lesions. The pressure device built in a stereotactic body frame controlled by a scaled screw which provides reproducible position.

\section{D PET/CT planning}

Using this technique for imaging tumor motion which can be incorporated in to target volume delineation specifically ITV with MIP (Maximum Intensity Projection).

\section{Motion management system}

Breath hold technique with $\mathrm{ABC}$ system: Planning is done on particular phase of 4D CT scan. Radiation can be delivered either during expiration or inspiration.

Real time positioning management with respiratory gating system: Breathing cycle is divided in to multiple separate segments either by phase or amplitude.

\section{Image guidance with 6 degree of freedom}

To guarantee accurate dose delivery and achieve pin point accuracy with six degree of freedom Transversal (Tx, Ty, Tz) and Rotational (roll, pitch yaw) set up uncertainty can be managed.

\section{Result}

Set up margin can be $5 \mathrm{~mm}$ or even smaller for lung SBRT. Abdominal compression reduces tumor motion range from $0-2 \mathrm{~cm}$ that can be reduced to sub-millimeter to $5 \mathrm{~mm}$. The motion amplitude was reduced to less than $5 \mathrm{~mm}$ in all direction. Decreases respiratory motion artifacts, MIP helps in defining ITV with 4D PET/CT based planning and motion management helps in creating good separation between target and sensitive organs helps reduce toxicity.

10 patients with Lung, Liver and Spine SBRT having mean \pm SD absolute setup errors and the mean \pm SD absolute immobilization errors were:

Before shift set up errors $\mathrm{Tx}=3.1 \pm 2.6 \mathrm{~mm} \mathrm{Ty}=3.4 \pm 2.9 \mathrm{~mm} \mathrm{Tz}=2.2$ $\pm 1.9 \mathrm{~mm}$,

$\mathrm{Rx}=0.77 \pm 0.57^{\circ}, \mathrm{Ry}=, 0.85 \pm 0.67^{\circ} \mathrm{Rz}=0.70 \pm 0.55^{\circ}$.

After shift $\mathrm{Tx}=0.4 \pm 0.5 \mathrm{~mm}$ Ty=0.5 $\pm 0.5 \mathrm{~mm} \mathrm{Tz}=, 0.5 \pm 0.7 \mathrm{~mm}$,

$\mathrm{Rx}=0.23 \pm 0.29^{\circ}, \mathrm{Ry}=0.33 \pm 0.35^{\circ} \mathrm{Rz}=0.22 \pm 0.28^{\circ}$

After completion of treatment $\mathrm{Tx}=0.4 \pm 0.6 \mathrm{~mm}$ Ty $=0.6 \pm 0.7 \mathrm{~mm}$ $\mathrm{Tz}=0.6 \pm 0.8 \mathrm{~mm}$,

$\mathrm{Rx}=0.23 \pm 0.27^{\circ}, \mathrm{Ry}=0.29 \pm 0.32^{\circ} \mathrm{Rz}=0.21 \pm 0.26^{\circ}$.

\section{Conclusion}

SBRT/SBRS is a rapidly expanding non-invasive treatment modality for delivery of ablative radiation doses. Advanced medical imaging, good immobilization and $4 \mathrm{D}$ motion management is the key for successful delivery of treatment. 